\title{
Investigation of Tolerable Laser Linewidth for Different Modulation Formats in CO-OFDM Systems
}

\author{
Divya Dhawan, Neena Gupta \\ PEC University of Technology, Chandigarh, India \\ Email:divyadhawan@pec.ac.in
}

How to cite this paper: Dhawan, D. and Gupta, N. (2017) Investigation of Tolerable Laser Linewidth for Different Modulation Formats in CO-OFDM Systems. Optics and Photonics Journal, 7, 92-100. https://doi.org/10.4236/opj.2017.75009

Received: November 30, 2016

Accepted: May 24, 2017

Published: May 27, 2017

Copyright ( $\odot 2017$ by authors and Scientific Research Publishing Inc. This work is licensed under the Creative Commons Attribution International License (CC BY 4.0).

http://creativecommons.org/licenses/by/4.0/

c) (†) Open Access

\begin{abstract}
The ideal behavior of communication system requires a single frequency carrier. In optical communication system, light is used as a carrier. Practical laser source has a finite linewidth due to variations in the frequency of operation, hence, resulting in undesired phase perturbations in the signal whereas the ideal requirement is the delta function spectral shape at the carrier frequency. The spectral shape gets broadened due to phase noise and is modeled as lorentzian shape. Linewidth is a measure of stability of laser phase noise with time. Coherent Optical Orthogonal frequency division multiplexing (CO-OFDM) along with the spectrally efficient Quadrature Amplitude Modulation (QAM) formats is emerging as one of the best solutions for future high speed fiber transmission systems. Though the coherent, receivers have advantages in terms of sensitivity and selectivity, laser phase noise is the main limitation of such systems as the laser phase noise further causes common phase rotation of all the subcarriers per symbol and also results in inter carrier interference. QAM formats are also susceptible to laser phase noise. Phase noise in coherent systems is governed by laser linewidth. Hence, it is very important to investigate the impact of laser linewidth in CO-OFDM systems. This paper investigates the tolerable laser linewidths for different QAM formats in a 40 Gbps COOFDM system.
\end{abstract}

\section{Keywords}

Laser Phase Noise, Linewidth, Coherent Detection, QAM, SER, OSNR

\section{Introduction}

With the tremendous increase in internet usage along with the requirement of high bandwidth applications, high speed and long haul optical communication systems are in great demand. This has compelled the researchers in the related 
area to take advantage of multicarrier transmission schemes along with the coherent detection and digital signal processing. Latest technological advancements in microelectronics such as high speed digital signal processors, analog to digital converters and digital to analog converters have made possible the use of digital signal processing in communication systems. This has further led to the development of software defined optical transmission [1]. A number of channel impairments such as chromatic dispersion, phase noise etc. can be mitigated effectively by employing DSP at the receiver or transmitter.

OFDM, a multicarrier transmission scheme is preferred choice for high speed optical communications as it is efficiently implemented using Inverse Fast Fourier Transform (IFFT) and is robust against various channel impairments. Intensity modulation and linear field modulation are the two variants of optical OFDM systems. Coherent detection is used for linear field modulation and direct detection is used for intensity modulation.

Direct Detection optical OFDM system finds applications in inexpensive short haul communication as there is lesser number of components at transmitter and receiver side as compared to coherent optical OFDM. However, there is requirement of frequency spacing between the optical carrier and OFDM band so as to avoid intermodulation distortion present in the diode. On the other hand, CO-OFDM is suitable for high speed long haul optical communication system [2]. High performance of CO-OFDM system requires narrow linewidth transmitter and local oscillator lasers along with the DSP algorithms for phase and frequency estimation at the receiver. Therefore, the hardware and cost involved are more. Digital phase estimation, computationally efficient FFT and IFFT, adaptive data rates due to software defined QAM constellations are the major advantages offered by COOFDM systems [1]. The software defined capability in COOFDM system presents numerous advantages in terms of different modulation formats for different subcarriers, mitigation of various imperfections such as laser drift, channel dispersion, optimization of various OFDM system parameters by monitoring of transmission channel characteristics. Due to these reasons, coherent detection is the most suitable choice for high-speed, high-spectral efficiency, dynamically reconfigurable optical networks suitable for long-distance transmission. By recovering the electric field in the two fiber polarizations, a coherent receiver allows information symbols to be encoded in all the degrees of freedom available in a fiber, leading to improved power and spectral efficiency [3].

Laser linewidth is defined as the width of the power spectral density of the emitted electric field. It is measured in the units of frequency, wavenumber or wavelength. It is typically the full width at half maximum. Coherent detection, OFDM and QAM are all susceptible to phase noise. The phase noise is characterized by laser linewidth. The phase noise results in phase rotation of all the subcarriers and hence leads to inter carrier interference which further results in loss of orthogonality [4]. Narrow linewidth lasers (nearly few $\mathrm{kHz}$ ) removes the degradation caused by phase noise. QAM modulation formats are very sensitive to the phase of the received symbol. Hence it is necessary to investigate the beha- 
vior in terms of Laser linewidth for a COOFDM system.

In this paper five different modulation formats are investigated 4-QAM, 16-QAM, Circular 4-QAM, Circular 16-QAM and optimized C16-QAM. As the order of modulation format increases, the phase noise affects the system performance more because the number of distinct phases to be identified is more as the order of modulation format is increased. One possible solution to resolve the issue of linewidth is by using a pilot tone having sufficient guard bandwidth so that the phase difference between transmitter's laser and local oscillator's laser can be detected [5]. Other methods include pilot aided phase noise compensation techniques.

The linewidth of the lasers used as well as the capability of the DSP to recover the constellation at extremely low SNR will further limit what constellation type that can be used in practice. The higher the order of the modulation format, the harder it is to perform phase tracking which put constraints on the linewidth of the lasers [6]. This paper investigates the phase noise effects arising from finite transmitter and local oscillator linewidth. The performance is investigated in terms of Symbol Error Rate as the laser linewidth varies at different OSNRs. From the graphs drawn, the values of tolerable linewidths for various modulation formats at different OSNRs are obtained for a target SER of 1e-3.

\section{Theoretical Details}

Mathematical model of a COOFDM system is given by [7]

$$
\begin{gathered}
y_{i k}=x_{i k} h_{k} e^{j \varnothing_{i}^{c}}+\epsilon_{i k}+n_{i k} \\
e^{j \varnothing_{i}^{c}} \triangleq \frac{1}{N_{s c}} \sum_{n} e^{j \varnothing(n)}
\end{gathered}
$$

$x_{i k}$ and $y_{i k}$ are the mQAM modulated data of the $k^{\text {th }}$ subcarrier in $i^{\text {th }}$ OFDM symbol before and after transmission, $h_{k}$ is the transmission channel impulse response at $k^{\text {th }}$ subcarrier, $n_{i k}$ is the complex white gaussian noise, $\in_{i k}$ is the intercarrier interference, $\varnothing_{i}^{c}$ represents the common phase error cause by laser phase drift or phase noise during optical fiber transmission, $\varnothing(n)$ is the laser phase noise.

The laser phase noise $\varnothing(n)$ is modeled as a random-walk process where $\varnothing_{i}^{\prime} s$ are independent, identically distributed Gaussian random variables with zero mean and variance $\left(\sigma^{2}\right)$ given by

$$
\sigma^{2}=2 \pi \Delta f T_{s}
$$

where $\Delta f$ is the combined laser linewidth and $T_{s}$ is the symbol period. The two main techniques to combat phase noise are Pilot aided phase noise compensation technique and RF pilot tone based phase noise compensation technique.

\section{Details of Simulation Set up}

The block diagram of simulation set up is shown in Figure 1. An OFDM signal with a data rate of $40 \mathrm{~Gb} / \mathrm{s}$ is generated from a pseudorandom binary sequence (PRBS) generator. 


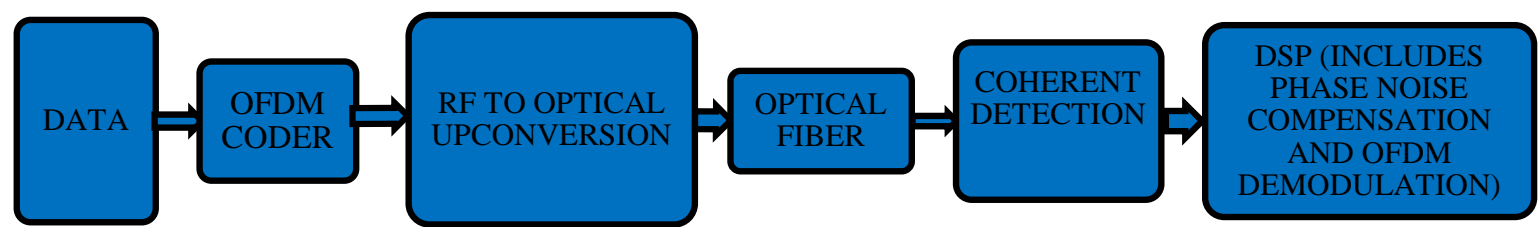

Figure 1. Block diagram of coherent optical communication system.

OFDM coder generates the electrical OFDM signal. The steps involved in OFDM coder are serial to parallel conversion, mapping, training symbols insertion, pilot carrier insertion, IFFT. An IFFT/FFT size of 128 is used. A Cyclic Prefix having $6.5 \%$ of the symbol length is added. A laser with $100 \mathrm{kHz}$ linewidth is used to generate a continuous signal at $193.1 \mathrm{THz}$. This is modulated with the OFDM signal in a null-biased IQ-Mach Zehnder Modulator (MZM) for COOFDM, an MZM up-convert the electrical OFDM signal into optical domain.

Optical Signal is then transmitted through a single mode fiber of length 3200 $\mathrm{km}$. Dispersion compensation is done in optical domain.

Coherent Detection at the receiver is carried out by two to four Quadrature Optical Hybrid. It combines the received optical signal and a local oscillator reference signal to generate four optical signals with a 90 degrees phase difference. Hence the in phase and quadrature components of RF baseband signal are obtained. After that DSP is applied to the I/Q components. The steps performed includes phase noise compensation, Cyclic prefix removal, Serial to parallel conversion, FFT, QAM demapping and finally parallel to serial conversion so as to retrieve the original data.

RF Pilot Tone based laser phase noise followed by pilot based equalization is used to remove the laser phase noise effects [8] in which RF pilot is added at the middle of OFDM band and subsequently used at the receiver to reverse the phase noise impairments. The residual phase noise left due to RF pilot getting distorted by OFDM subcarriers is removed by pilot carriers.

\section{Results and Discussion}

To use the bandwidth efficiently advanced and spectrally efficient modulation formats are used. In this paper, modulation formats used are Rectangular 4QAM, Rectangular 16-QAM, Circular 4-QAM, Circular 16-QAM and optimized C-16 QAM. Circular-QAM schemes are widely employed in satellite broadcasting systems. Smaller amplitude fluctuation in circular QAM as compared to rectangular-QAM, which results in fewer amplitude levels [9] has created the research interest for their usage in optical communication systems as well.

In this paper laser linewidth requirements are investigated for the mentioned modulation formats and SER floors for different laser linewidth and different modulation formats are investigated. Figure 2 shows the symbol error rate versus Laser linewidth for 4 QAM modulation format. The graph has been plotted for different OSNRs ranging from $10 \mathrm{~dB}$ to $40 \mathrm{~dB}$.

It is observed from the graph in Figure 2 that with the increase in Laser linewidth, the performance of the system deteriorates in terms of Symbol Error Rate 
(SER). For 4-QAM format, the performance in terms of SER is almost consistent up to $100 \mathrm{KHz}$. After that SER starts increasing. The system starts having significant deterioration at $500 \mathrm{kHz}$ and becomes more severe at $1 \mathrm{MHz}$. Hence for the systems using 4-QAM format the tolerable laser linewidth as obtained from the graph is $2.3 \mathrm{MHz}$ at $15 \mathrm{~dB}$ OSNR, $5.2 \mathrm{MHz}$ at $20 \mathrm{~dB}$ OSNR, $5.8 \mathrm{MHz}$ for 25 $\mathrm{dB}$ and higher. These values are for target SER $1 \mathrm{e}-3$ at a distance of $3200 \mathrm{~km}$.

Figure 3 shows the SER floor for 16 QAM modulation format by increasing the laser linewidth. It is observed that the same trend follows here also as in 4 QAM but now the SER is consistent up to $10 \mathrm{kHz}$, starts deteriorating at $50 \mathrm{kHz}$

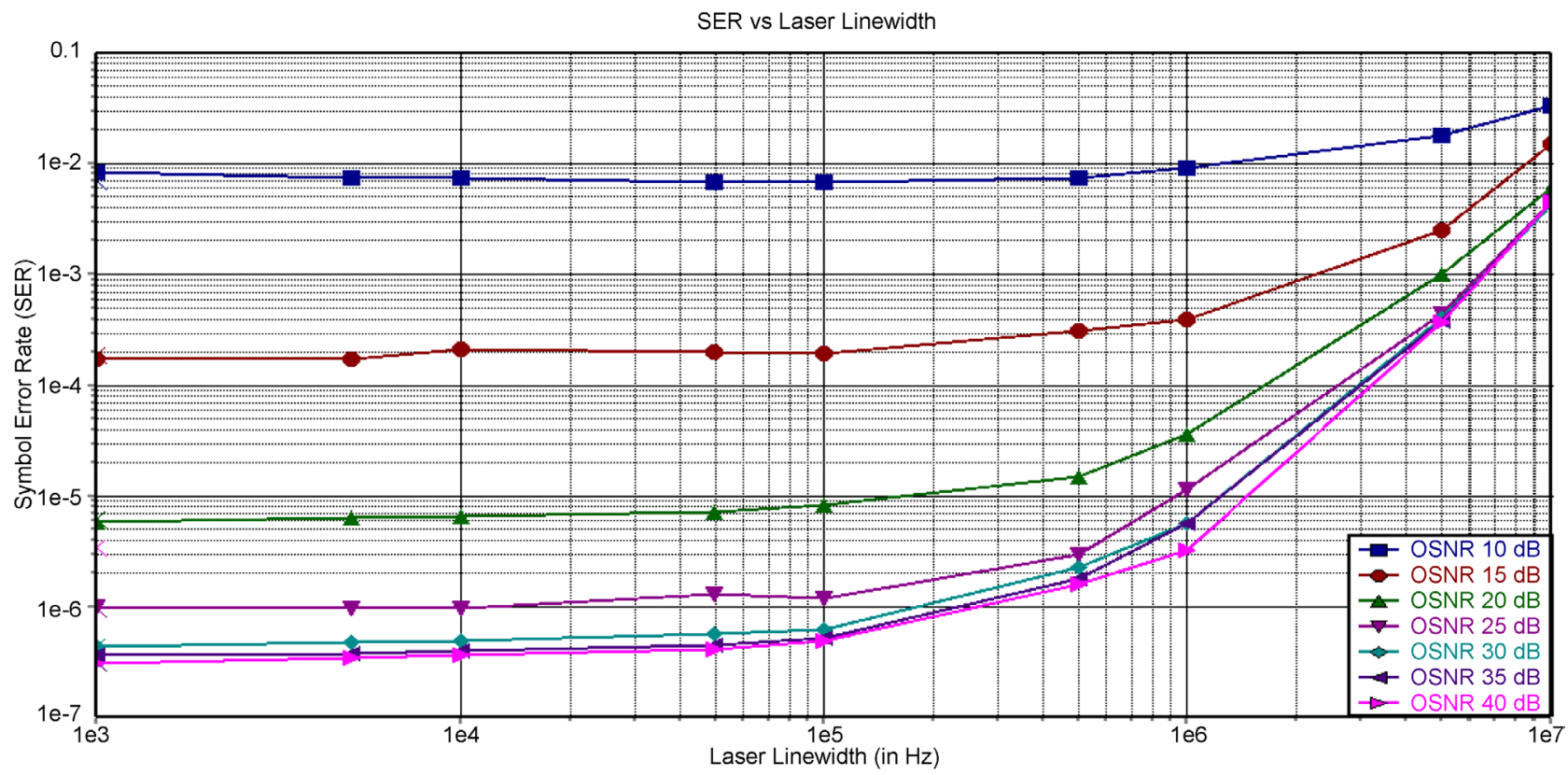

Figure 2. SER vs. laser linewidth (4 QAM).

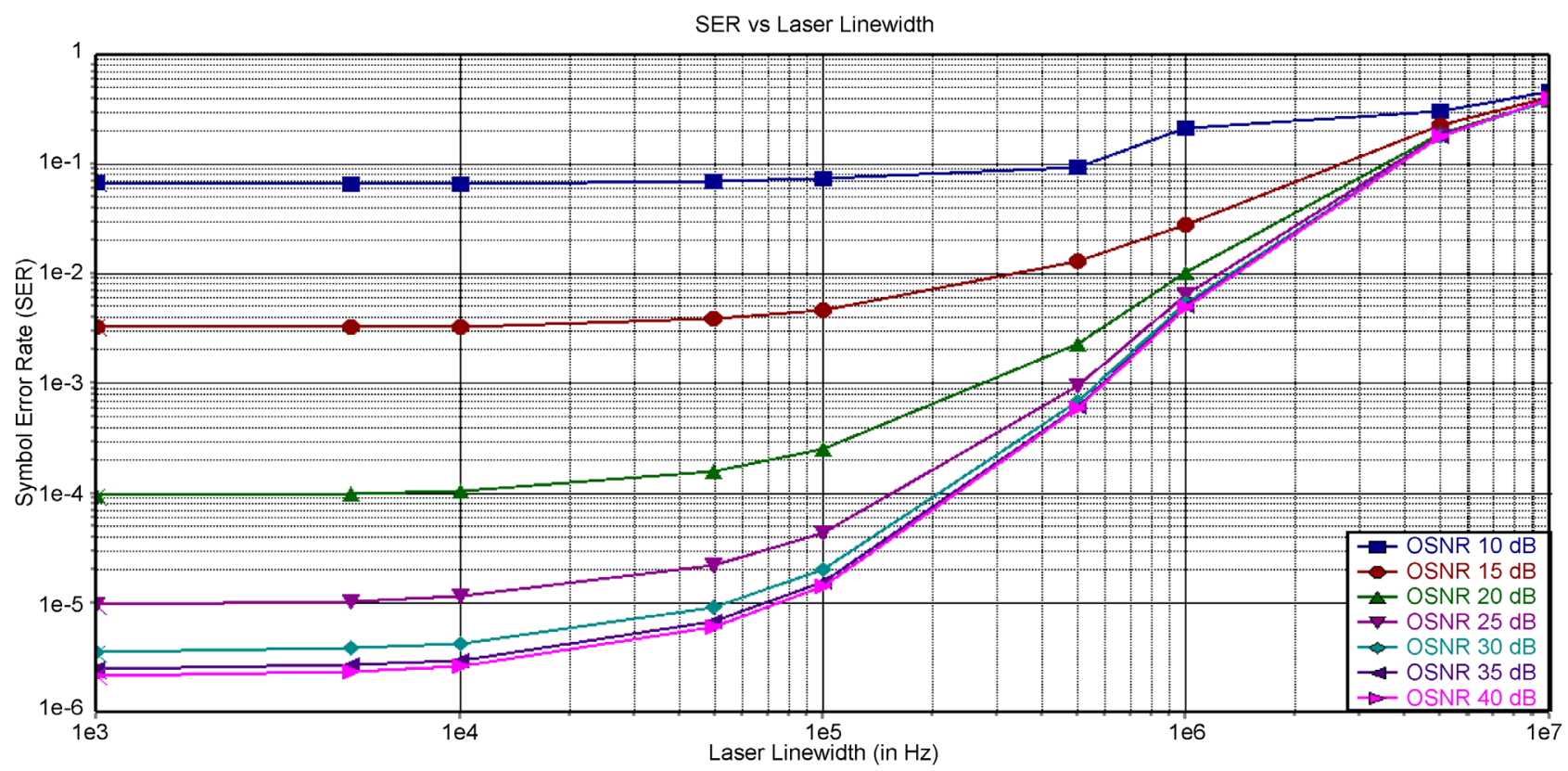

Figure 3. SER vs. laser linewidth (16 QAM). 
which becomes faster at $100 \mathrm{kHz}$. Hence for the systems using 16-QAM format the tolerable laser linewidth is $300 \mathrm{kHz}$ at $20 \mathrm{~dB}$ OSNR, $550 \mathrm{kHz}$ for $25 \mathrm{~dB}$ OSNR, $600 \mathrm{KHz}$ for $30 \mathrm{~dB}$ and higher. Also it is to mention that $15 \mathrm{~dB}$ OSNR is not sufficient to have SER $<1 \mathrm{e}-3$ at a distance of $3200 \mathrm{~km}$. In case of 16 QAM modulation format graphs for different OSNRs exhibit the same performance at $10 \mathrm{MHz}$ whereas it is not so in the case of 4 QAM.

Circular M QAM modulation format has smaller amplitude fluctuation as compared to rectangular-QAM, which results in fewer amplitude levels. This feature of circular QAM modulation format has attracted the interest and its performance is also investigated and compared with rectangular QAM. Figures 4-6 show SER variation with linewidth for Circular 4 QAM, Circular 16 QAM and Optimized C16 QAM respectively.

The performance of circular 4-QAM format follows the same trend as that of rectangular 4-QAM format.SER is nearly consistent up to $100 \mathrm{kHz}$. After that it starts deteriorating at $500 \mathrm{kHz}$ and SER deterioration becomes fast after $1 \mathrm{MHz}$ (Figure 4).

Similarly for C16-QAM and optimized C16-QAM, SER starts deteriorating rapidly after $100 \mathrm{kHz}$.

Table 1 shows the tolerable linewidths for different modulation formats for various OSNRs at a distance of $3200 \mathrm{~km}$ for a target SER of $1 \mathrm{e}-3$.

The tolerable linewidth values of rectangular 4-QAM format are small as compared to circular 4-QAM format. The difference is $0.2 \mathrm{MHz}, 0.3 \mathrm{MHz}, 0.4$ $\mathrm{MHz}$ at $15 \mathrm{~dB}, 20 \mathrm{~dB}$ and $25 \mathrm{~dB}$ respectively and after that the performance is same.

For circular 16-QAM format, the tolerable linewidth is increased by nearly 70 $\mathrm{kHz}, 50 \mathrm{kHz}, 90 \mathrm{kHz}, 95 \mathrm{kHz}, 90 \mathrm{kHz}$ at OSNR values of $20 \mathrm{~dB}, 25 \mathrm{~dB}, 30 \mathrm{~dB}, 35$

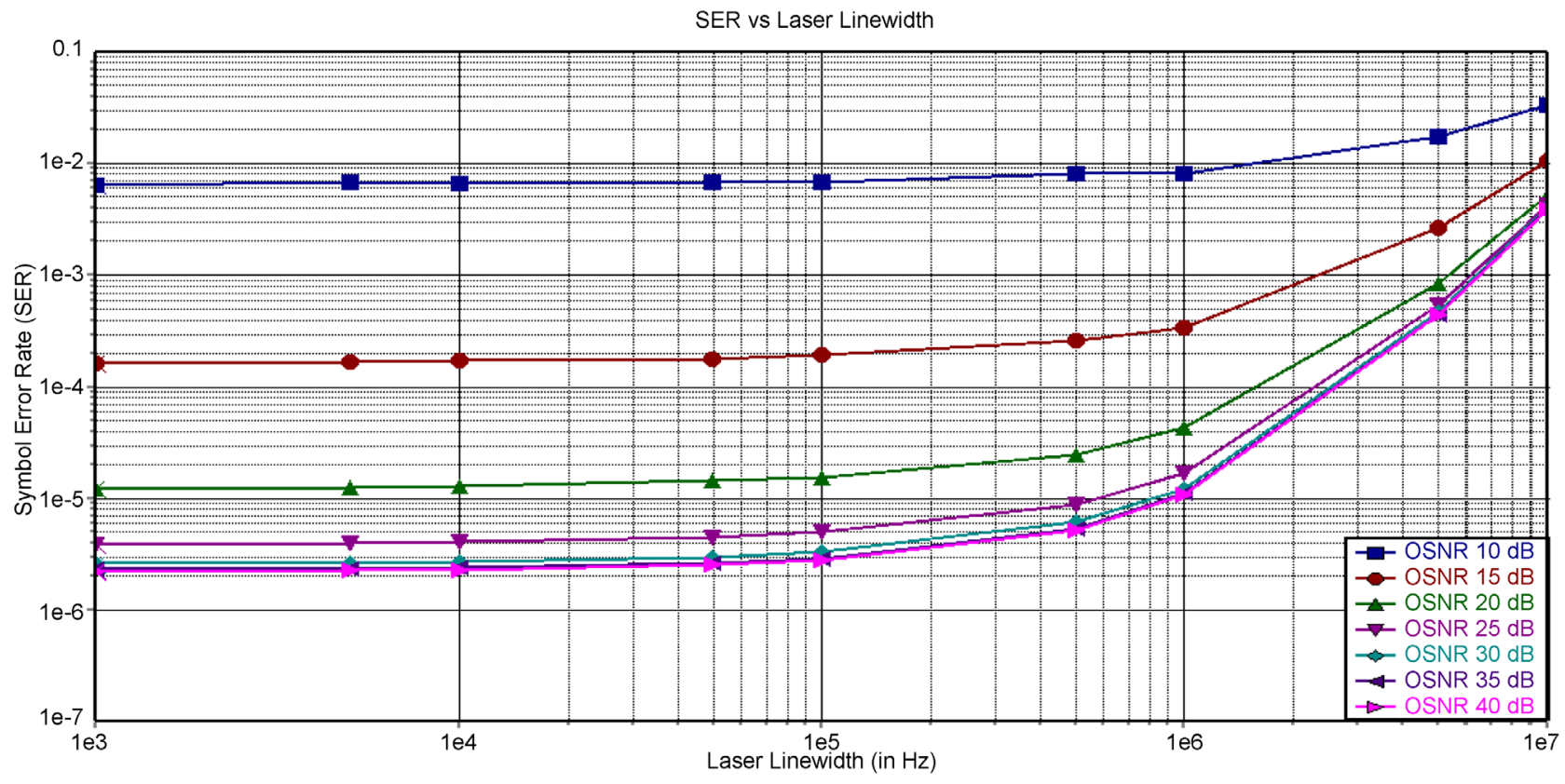

Figure 4. SER vs. laser linewidth (circular 4 QAM). 


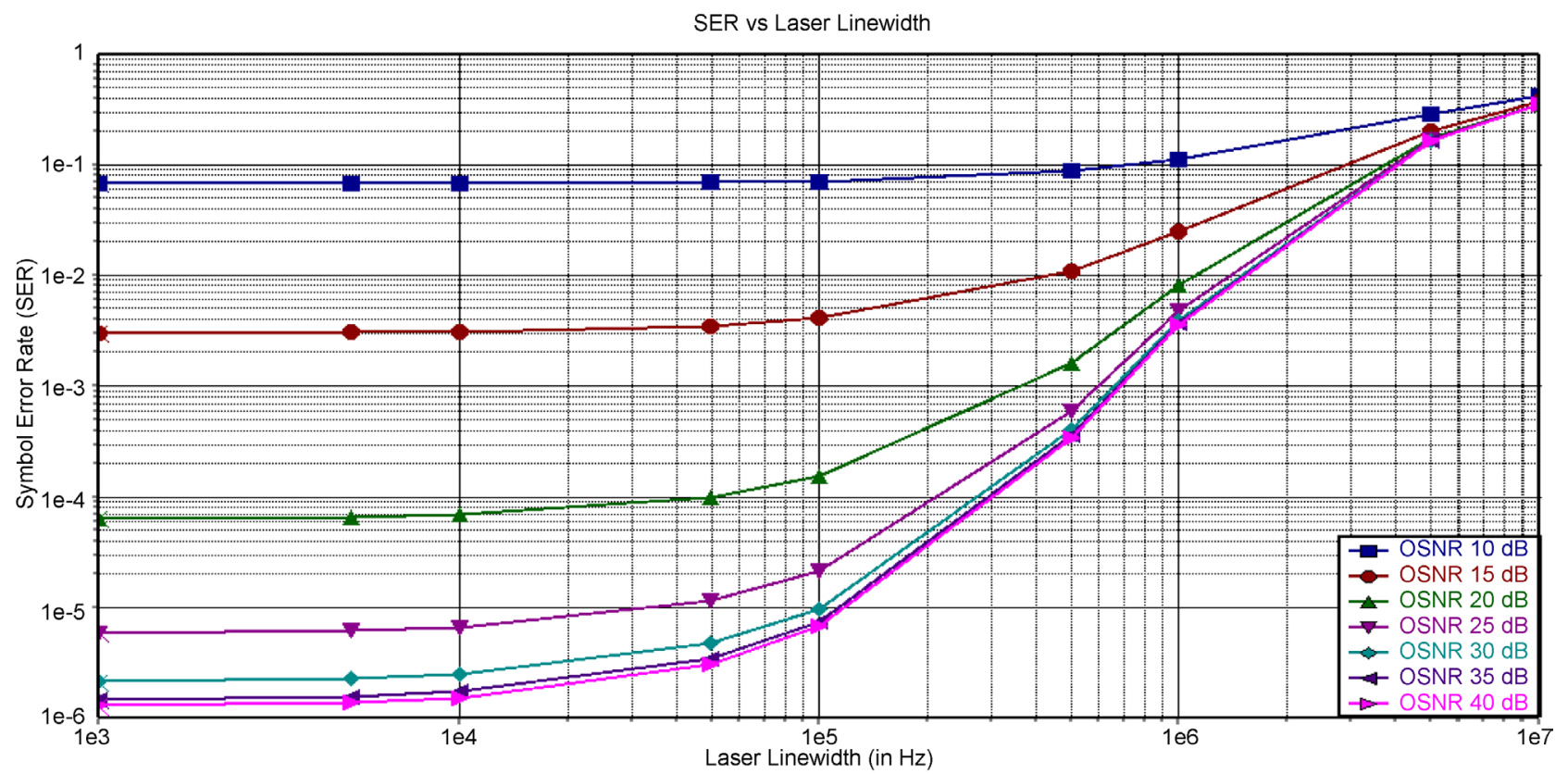

Figure 5. SER vs. laser linewidth (circular 16 QAM).

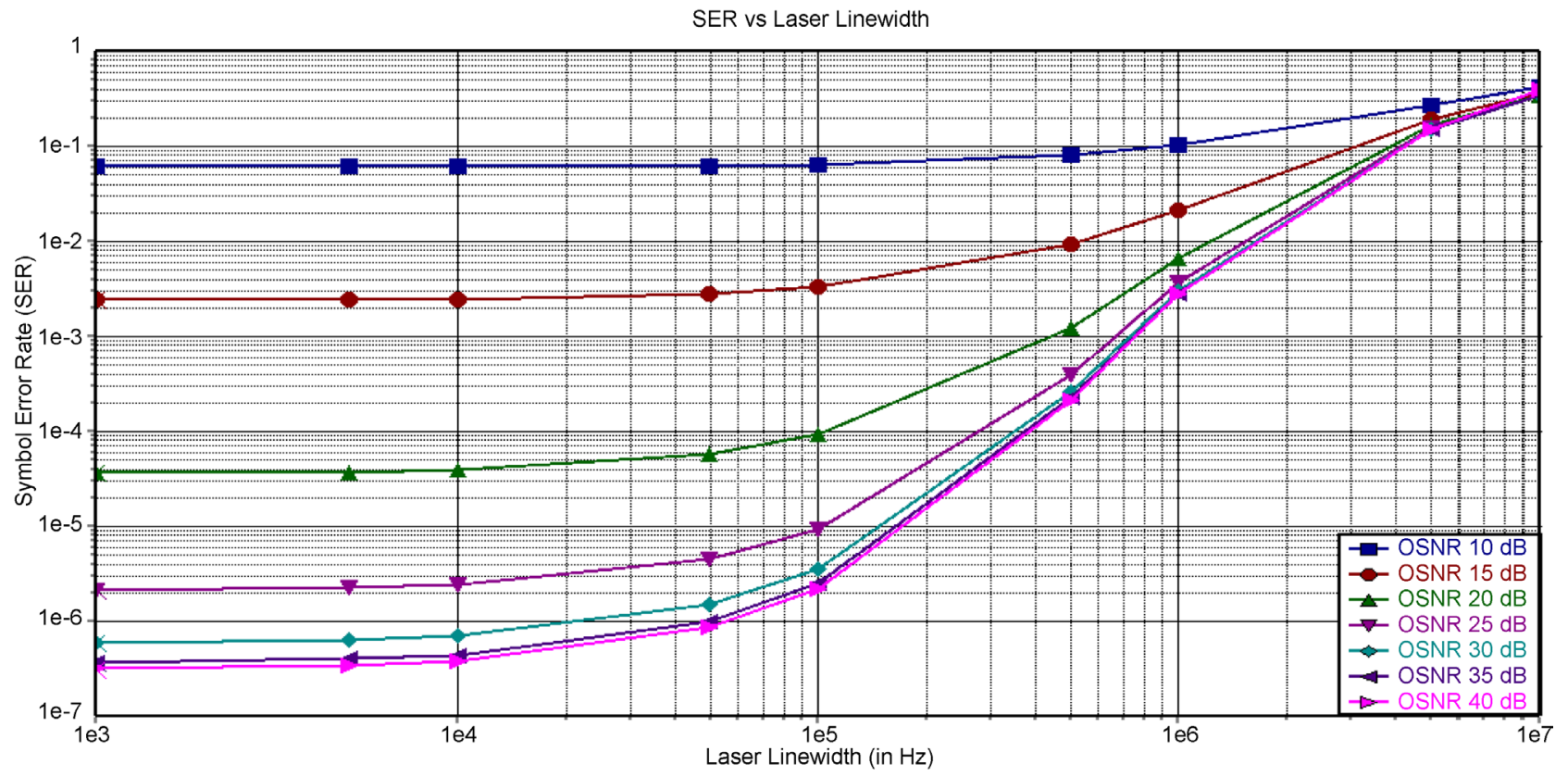

Figure 6. SER vs. laser linewidth (optimized C16 QAM).

Table 1. Tolerable linewidth for different modulation formats for various OSNRs.

\begin{tabular}{|c|c|c|c|c|c|c|c|}
\hline \multirow{2}{*}{ Modulation Format } & \multicolumn{7}{|c|}{ OSNR } \\
\hline & $10 \mathrm{~dB}$ & $15 \mathrm{~dB}$ & $20 \mathrm{~dB}$ & $25 \mathrm{~dB}$ & $30 \mathrm{~dB}$ & $35 \mathrm{~dB}$ & $40 \mathrm{~dB}$ \\
\hline 4-QAM & Not Achieved & $2.3 \mathrm{MHz}$ & $5.2 \mathrm{MHz}$ & $5.8 \mathrm{MHz}$ & $6.5 \mathrm{MHz}$ & $6.5 \mathrm{MHz}$ & $6.5 \mathrm{MHz}$ \\
\hline 16-QAM & Not Achieved & Not Achieved & $300 \mathrm{kHz}$ & $550 \mathrm{kHz}$ & $600 \mathrm{kHz}$ & $605 \mathrm{kHz}$ & $610 \mathrm{kHz}$ \\
\hline C4-QAM & Not Achieved & $2.5 \mathrm{MHz}$ & $5.5 \mathrm{MHz}$ & $6.2 \mathrm{MHz}$ & $6.5 \mathrm{MHz}$ & $6.5 \mathrm{MHz}$ & $6.5 \mathrm{MHz}$ \\
\hline C16-QAM & Not Achieved & Not Achieved & $370 \mathrm{kHz}$ & $600 \mathrm{kHz}$ & $690 \mathrm{kHz}$ & $700 \mathrm{kHz}$ & $700 \mathrm{kHz}$ \\
\hline Optimized C16-QAM & Not Achieved & Not Achieved & $500 \mathrm{kHz}$ & $700 \mathrm{kHz}$ & $780 \mathrm{kHz}$ & $790 \mathrm{kHz}$ & $800 \mathrm{kHz}$ \\
\hline
\end{tabular}


$\mathrm{dB}$ and $40 \mathrm{~dB}$ respectively when compared to rectangular 16-QAM format. For optimized C16-QAM format, this increase is $200 \mathrm{kHz}, 150 \mathrm{kHz}, 180 \mathrm{kHz}, 185$ $\mathrm{kHz}, 190 \mathrm{kHz}$ at $20 \mathrm{~dB}, 25 \mathrm{~dB}, 30 \mathrm{~dB}, 35 \mathrm{~dB}$ and $40 \mathrm{~dB}$ respectively when compared to rectangular 16-QAM format and is in range $80-100 \mathrm{kHz}$ when compared to regular circular 16-QAM format.

Hence it can be concluded that as OSNR is increased, the tolerable linewidth also increases. Also as the order of modulation becomes higher, the tolerable linewidth decreases. However comparing the rectangular QAM and circular QAM formats, it is observed that rectangular 4-QAM format outperforms the circular 4-QAM format whereas circular 16-QAM format outperforms the rectangular 16-QAM format. Optimized C16-QAM format has further better performance.

\section{Conclusion}

Optical OFDM, Coherent detection and QAM modulation format are affected by phase noise. Phase noise is characterized by Laser linewidth. Hence, laser linewidth requirements are investigated for rectangular and circular 4 and 16 QAM modulation formats. At an OSNR of $25 \mathrm{~dB}, 4$ QAM modulation formats can use lasers of linewidth $5 \mathrm{MHz}$ for $\mathrm{SER}<1.0 \mathrm{E}-3$ whereas the required value for 16 QAM modulation format is $500 \mathrm{kHz}$. OSNR requirements are less for circular QAM as compared to rectangular QAM. Also rectangular 4 QAM outperforms circular QAM whereas circular 16 QAM outperforms rectangular 16 QAM.

\section{References}

[1] Yi, X.W., Shieh, W. and Ma, Y. (2008) Phase Noise Effects on High Spectral Efficiency Coherent Optical OFDM Transmission. Journal of Lightwave Technology, 26, 1309-1316. https://doi.org/10.1109/JLT.2008.919368

[2] Hussin, S., Puntsri, K. and Noe, R. (2011) Performance Analysis of Optical OFDM Systems. 20113 rd International Congress on Ultra Modern Telecommunications and Control Systems and Workshops (ICUMT), Budapest, 5-7 October 2011, 1-5.

[3] Ip, E.M. and Kahn, J.M. (2010) Fiber Impairment Compensation Using Coherent Detection and Digital Signal Processing. Journal of Lightwave Technology, 28, 502519. https://doi.org/10.1109/JLT.2009.2028245

[4] Hmood, J.K. (2009) Phase Noise Compensation for Coherent Orthogonal Frequency Division Multiplexing in Optical Fiber Communications System. Iraqi Journal of Applied Physics, 5, 3-10.

[5] Lowery, A.J. and Du, L.B. (2011) Optical Orthogonal Division Multiplexing for Long Haul Optical Communications: A Review of the First Five Years. Optical Fiber Technology, 17, 421-438.

[6] Eriksson, T.A. (2014) Multidimensional Modulation Formats for Coherent Optical Communication Systems Coherent Optical Communication Systems. PhD Thesis, Chalmers University of Technology, Gothenburg, 8-9.

[7] Varughese, S.J., Mathew, V., Swain, S., Venkitesh, D. and Koilpillai, D.R. (2015) 200 G System with PDM-16QAM: Performance Evaluation and Trade-Offs. 201521 st National Conference on Communications, (NCC2015), February 27 2015, 1-6. http://www.ee.iitm.ac.in/ ee11b038/docs/ncc_paper.pdf 
[8] Jansen, S., Morita, I., Takeda, N. and Tanaka, H. (2007) 20-Gb/s OFDM Transmission over 4160-km SSMF Enabled by RF-Pilot Tone Phase Noise Compensation. National Fiber Optic Engineers Conference, Anaheim, 25 March 2007, PDP15.

[9] Navarro, J.R., Kakkar, A., Pang, X., Olmedo, M.I., Ozolins, O., Da Ros, F., Piels, M., Schatz, R., Zibar, D., Jacobsen, G. and Popov, S. (2016) Two-Stage n-PSK Partitioning Carrier Phase Recovery Scheme for Circular mQAM Coherent Optical Systems. Photonics, 3, 37. https://doi.org/10.3390/photonics3020037

Submit or recommend next manuscript to SCIRP and we will provide best service for you:

Accepting pre-submission inquiries through Email, Facebook, LinkedIn, Twitter, etc. A wide selection of journals (inclusive of 9 subjects, more than 200 journals) Providing 24-hour high-quality service User-friendly online submission system Fair and swift peer-review system Efficient typesetting and proofreading procedure Display of the result of downloads and visits, as well as the number of cited articles Maximum dissemination of your research work

Submit your manuscript at: http://papersubmission.scirp.org/ Or contactopj@scirp.org 